\title{
APORTACIONES DE LA CRÍTICA LITERARIA NEOPLATÓNICA A LA COMPRENSIÓN DE PLATÓN COMO ESCRITOR
}

The purpose of this paper is to point to the fact that it is possible to find a very sensitive literary criticism in neoplatonists. The attention of the authoress focuses on the Anonymous Prolegomena ad Platonis philosophiam. The treatise includes a complete approach to platonic dialogues where there are ideas as suggestive as the relations between author-book-reader.

Vamos a centrar nuestro estudio sobre crítica literaria del neoplatonismo tardío en unos Prolegomena, atribuidos falsamente a Olimpiodoro ', adscritos a la escuela de Alejandría y datados en el s. VI. Es una obra escolar y sistemática que constituye por ello mismo un exponente magnífico de la crítica literaria de los comentadores neoplatónicos. Comenzamos con una exposición descriptiva, siguiendo el orden de la obra, de los aspectos tratados. Tratamos de llegar a una comprensión global de los conceptos operativos usados y, en segundo lugar, demostrar la incidencia de criterios no siempre tan estrictamente filosóficos como parecer pudiera cuando se enfrentan, aunque sea de manera indirecta, con Platón escritor. Veremos cómo el hecho literario en sí, en todas sus oblicuaciones y en todos sus planos queda presentado en una perspectiva asombrosamente rica.

La primera novedad que presenta frente a la Isagogé de Albino es que se inicia con el problema global, todavía candente, del carácter paradójico de la escritura en un filósofo que la ha atacado de plano en una de sus obras literarias más perfectas, en el Fedro. La argumentación del comentarista, consciente de la contradicción, es que Platón ha querido con ello imitar el comportamiento de la divinidad que ha creado tantos productos corpóreos como incorpóreos. De estos últimos serian las enseñanzas no escritas, que, por lo tanto, se conciben como su-

1 Para toda la cuestión de la autoría del comentario: L. G. Westerink, Anonymous Prolegomena to platonic philosophy. Amsterdam 1962, pp. IX-XLI. 


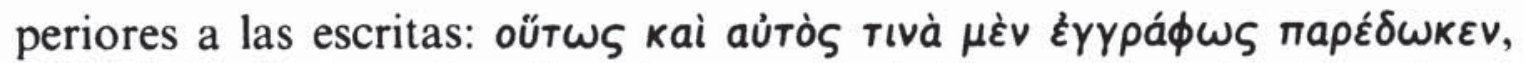

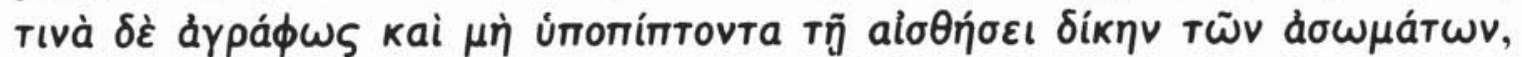

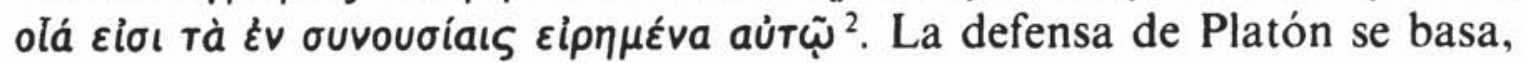
en un nivel más pragmático y también más intrínseco, en las peculiares características de la forma literaria elegida que se presenta como la más

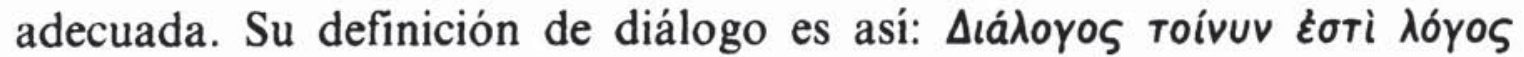

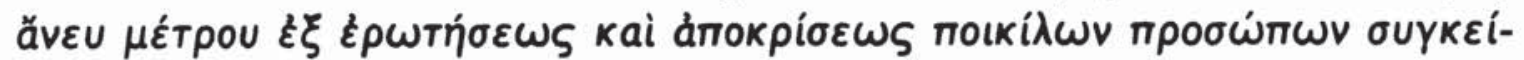

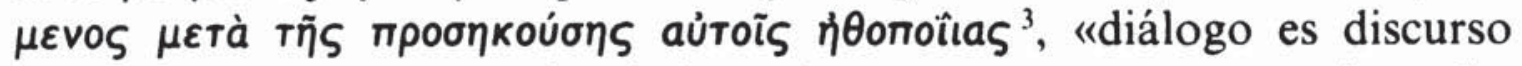
sin medida, compuesto sobre la base de preguntas y respuestas de variados personajes con acompañamiento de la debida caracterización" (cum debita morum pictura). Característica estrictamente privativa del género es el hecho de que no tenga metro que es lo que lo diferencia de tragedia y comedia, al menos en el nivel más inmediatamente formal, dado que éstas participan de los demás elementos constitutivos: es decir, del trenzado pregunta-respuesta y de una necesaria caracterización de los personajes. Le extraña el hecho de que Platón, que parece repeler cualquier actividad artística variopinta, en tanto que imitación escoja este medio de expresión. Encuentra otra nueva diferencia con tragedia y comedia en el tratamiento de los personajes, pues en éstas no hay cambio:

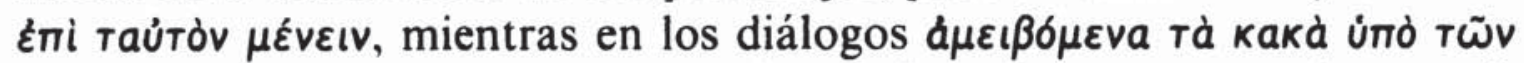
áya $\theta \tilde{\omega} v$. Las afinidades entre una forma literaria y otra quedan manifiestas en la medida en que se vuelve tan necesario encontrar las diferencias. El diálogo en su concepción resulta una forma literaria perfecta

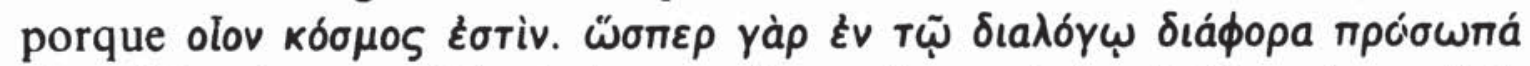

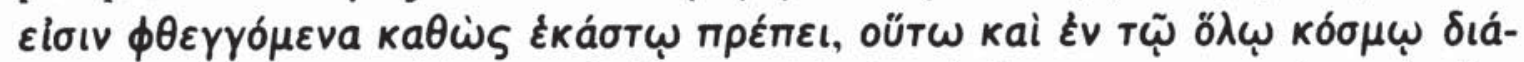

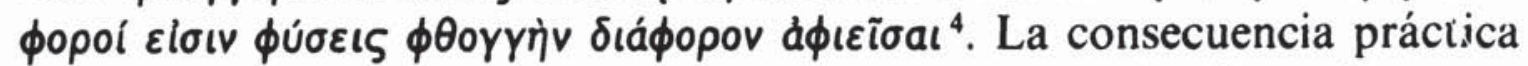
del aserto admite una relectura interesante «... y en el diálogo hay personajes unos que refutan y otros que son refutados y nuestra alma, como un juez, unas veces da la razón a unos, otras, en cambio, a otros» ${ }^{5}$. Parece un cierto alegato a favor de la aparente falta de dogmatismo de los diálogos y se incide en la importancia del punto de vista del lector. La lectura se vuelve un proceso mucho más «transitivo» de

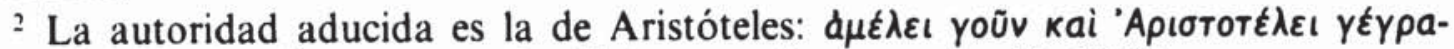

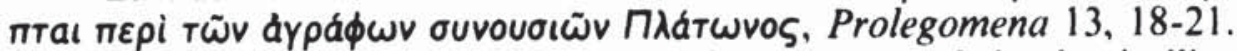

${ }^{3}$ Anonymous Prolegomena XIV; es importante señalar la similitud, por no decir

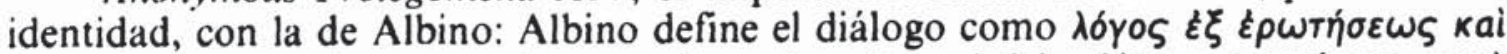

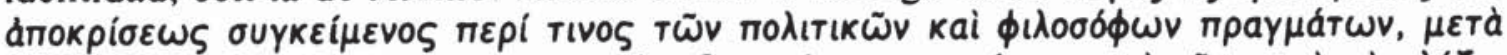
ті் катабкєuñs. Lo mismo puede decirse de la de Diógenes Laercio, que sí es idéntica a la de Albino, cf. III 48.

4 Anonymous Prolegomena... XV 1-10.

5 Anonymous Prolegomena... XV 25-27. 
lo que ha sido después. Merece la pena insistir en que ya en la Retórica de Aristóteles aparecen tipificados los tres elementos claves de la técnica: «Porque consta de tres cosas el discurso: el que habla, sobre lo que se habla y a quién" ${ }^{6}$. Asociado al oyente aparece alli mismo el término крเтฑ́s. Es insistente la justificación del género elegido por Platón porque es como un $\kappa \delta ́ \sigma \mu \varsigma_{5}$ y continúa el comentarista con la habitual ${ }^{7}$ parafernalia neoplatónica estableciendo, una vez más, la vieja analogía microcosmo-macrocosmo ${ }^{8}$ : como hay distintas almas, unas superiores a otras, así también hay distintos personajes en los diálogos. Como suele ser habitual, tanto que no merece la pena insistir ni en la fuente ni en el vigor y la fecundidad de la idea, la analogía se completa con el apoyo

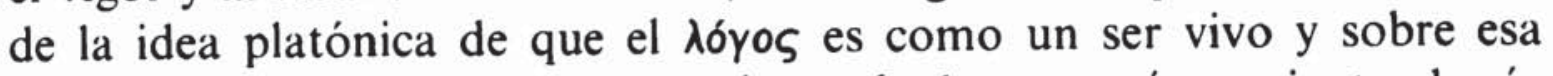

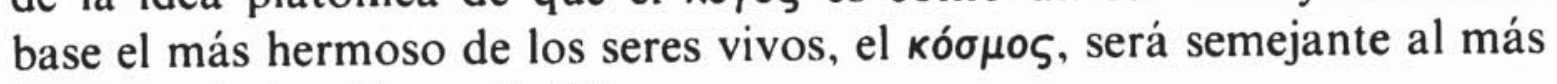

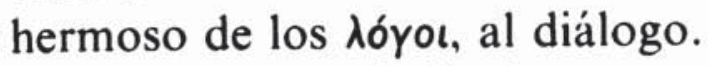

La siguiente de las bases en que apoya su defensa es la idea de la utilidad pedagógica y señala, en un argumento muy viejo, que somos especialmente amantes de las narraciones y esta característica se puede reescribir diciendo que el ser humano es especialmente susceptible a la literatura y ello porque, estructuralmente, el alma humana es esencialmente mimética. El carácter de «encantamiento» de la escritura adquie-

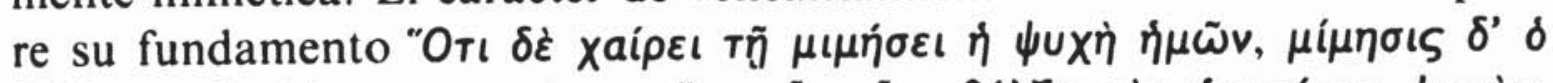

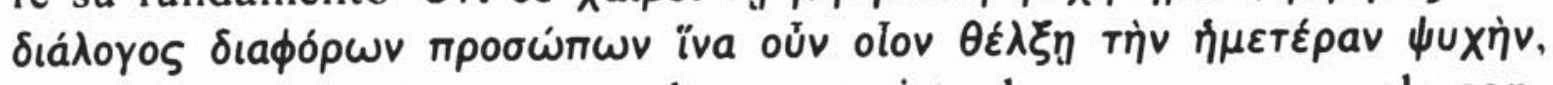

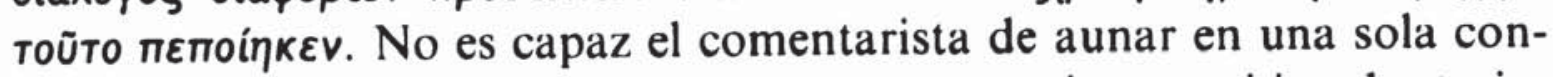
clusión las premisas planteadas, que parecen asociarse casi involuntariamente: somos, de niños especialmente amantes de las narraciones en general, $\phi i \lambda o \mu u ́ \theta o u s$, y ello prueba que nuestra alma se complace con la imitación y, en segundo lugar, es más fácil memorizar no una enseñanza abstracta sino encarnada en una situación ${ }^{9}$. La conclusión es evidente: también el aprendizaje se efectúa por medio de imitaciones, porque el ser humano es capaz de abstraer de las múltiples realizaciones de un fenómeno. Y asimismo, y ello constituye la piedra de toque y la clave actual de la diferencia entre inteligencia artificial e inteligencia humana,

\footnotetext{
- Aristóteles, Retórica I 3, 1358b, la traducción es de A. Tovar, Madrid 1985 (1953).

7 La llamo habitual en el sentido de que nuestro autor es casi el penúltimo representante de la corriente y que esta idea tiene, dejando a un lado su presencia implícita en el Timeo platónico, cf. G. Boas, "Macrocosm and Microcosm», Dictionary of the History of Ideas, III, Nueva York 1977, pp. 126-131, siendo aplicada a la obra literaria en este mismo sentido desde Proclo.

" Para toda la cuestión de la analogía macrocosmo-microcosmo remito a J. A. Coulter, The literary microcosm. Theories of interpretation of the later neoplatonists. Leiden 1976, pp. 95-126.

"Anonymous Prolegomena... XV 17-19.
} 
el ser humano es capaz de imitar fuera del estimulo aprendido un comportamiento, un razonamiento. $\mathrm{Y}$ una imitación más es la literatura. $\mathrm{O}$ sea, no sólo el hombre es un ser especialmente susceptible a la literatura sino que lo es porque en la estructura de sus capacidades intelectuales mínimas se encuentra la imitación, en sentido amplio, como un constituyente inmediato. La argumentación sobre la mímesis continúa en un

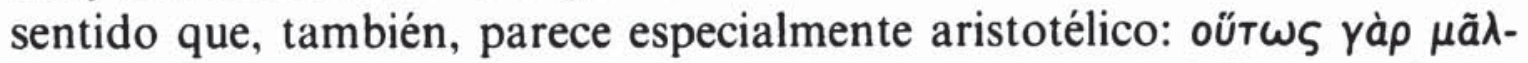

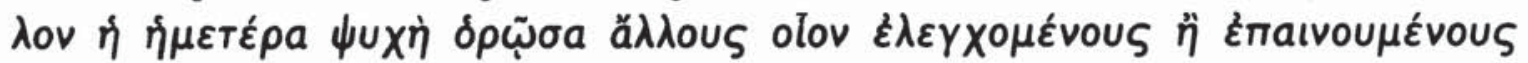

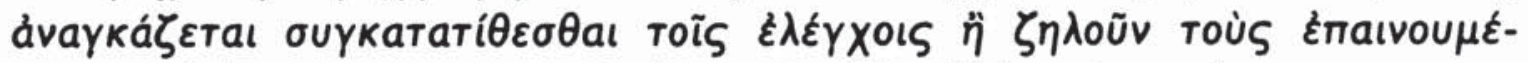

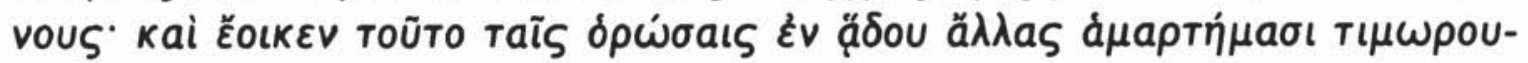

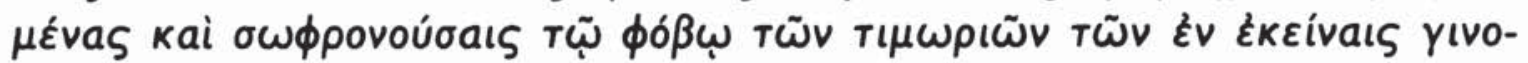
$\mu \varepsilon \dot{\varepsilon} v \omega v^{10}$ : no es que el modelo imitativo tenga que estar en presencia sino que es igualmente eficaz en contrario, e incluso de manera anticipada y podríamos decirlo así, como en el concepto de tragedia en Aristóteles, de manera traslaticia, "y ello se asemeja a las almas que ven en el Hades a otras castigadas por sus yerros y son prudentes por miedo de los castigos de aquéllas». Por supuesto no se está queriendo decir que haya una influencia directa ni mucho menos sino que parece como si el concepto Mímesis en el Neoplatonismo tardío hubiera sinergizado las dos concepciones, platónica y aristotélica, convirtiéndose en auténtica columna vertebral de la psicología de la escuela y principio básico de construcción y deconstrucción, esto es lo importante, del mundo. El siguiente argumento me parece especialmente conclusivo: «usa del diálogo porque es la forma perfecta por naturaleza para imitar la dialéctica,

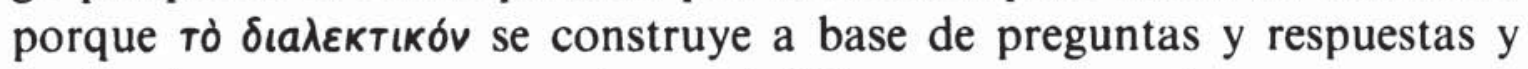
de la misma manera se construye el diálogo con preguntas que nos ayudan a sacar a la luz nuestro conocimiento previo, porque el alma humana no es una tablilla sin escritura». La última justificación del modelo literario empleado es verdaderamente sorprendente: "en séptimo lugar para que prestemos atención a lo que se dice por la variedad de los personajes que hablan, porque si fuera una sola persona la que enseña siempre podríamos, por decirlo así, adormilarnos..." ". La base argumental ha pasado de lo puramente literario, la adecuación de la obra al fin, a una fundamentación ontológica de lo literario y a una referencia al lector. Esta referencia es doble: una próxima, casi de cotidianeidad: la obligación del comunicador de crear un producto que mantenga la

10 Anonymous Prolegomena... XV 27-29. Es la traducción a otro lenguaje del mismo principio de la Poética 6, 49b25 ss., cf. A. Díaz Tejera, Ayer y hoy de la tragedia, Sevilla 1989, pp. 54-60.

"Anonymous Prolegomena... XV. 
atención y otra segunda de carácter más mediato: el vehículo comunicativo tiene su hondo fundamento en la psicología del lector.

Partiendo de la base de que el diálogo es un ser vivo, establece la proporcionalidad diálogo-mundo habitual en el neoplatonismo tardio ${ }^{12}$. Y merece la pena destacar algún rasgo: el análisis parte de categorías no literarias. Si el diálogo es un cosmos debe tener los mismos constituyentes que cualquier otro cosmos. De entre los constituyentes, a la materia, $u \lambda \eta$, es proporcional el tiempo, lugar y personajes con el añadido de que los personajes son el elemento imprescindible y los otros no. Los

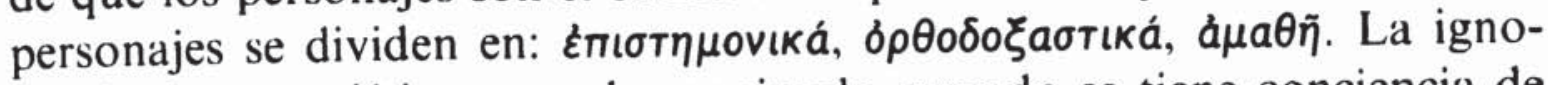
rancia de estos últimos puede ser simple, cuando se tiene conciencia de la ignorancia, doble cuando no se es consciente, máxima cuando sabiendo que no sabe y en presencia de la verdad no lo reconoce y sofistica cuando ignorando algo intenta ocultar su ignorancia con discursos convincentes ${ }^{13}$. En cuanto a los personajes, no son ni enteramente pro-

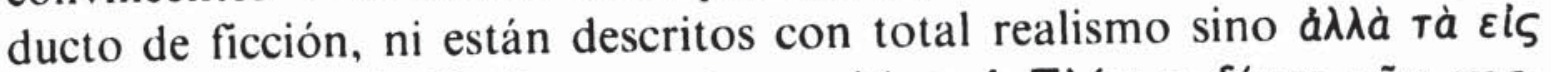

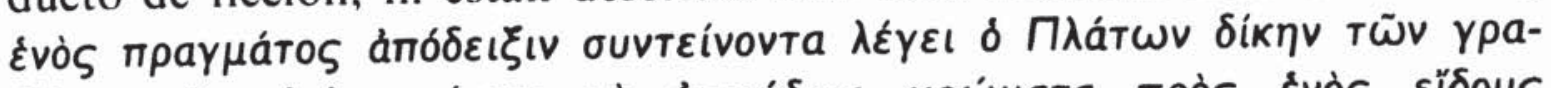

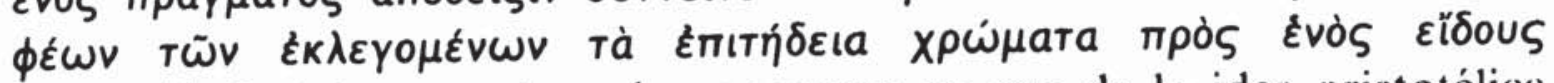

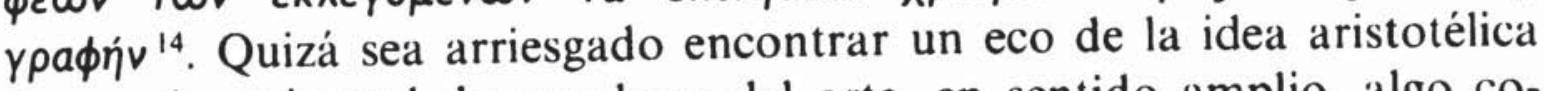
de que lo universal, lo que hace del arte, en sentido amplio, algo común, no está en lo que se ciñe estrictamente a un sucedido histórico. En cuanto al lugar entiende que no son casuales las localizaciones y concede especial importancia al hecho de que se produzcan con motivo de festividades de dioses como si el diálogo constituyera un himno a la divinidad. El Timeo tiene lugar en las Bendidias, el Parménides en las Panatenaicas. En cuanto al lugar señala que mientras vivió Sócrates los escenarios son atenienses, una vez muerto ya no. Así el Banquete tiene lugar en la casa de Agatón, La República en el Pireo, el Fedro en el santuario de las Musas y el Timeo en un sitio sin concretar.

En cuanto al carácter del diálogo éste se asimila con el $\varepsilon$ lठos y tiene

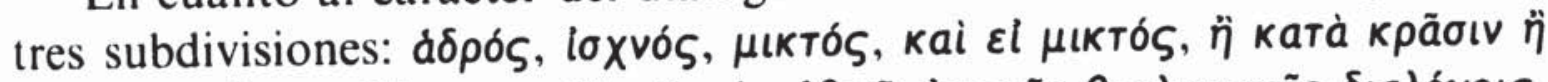

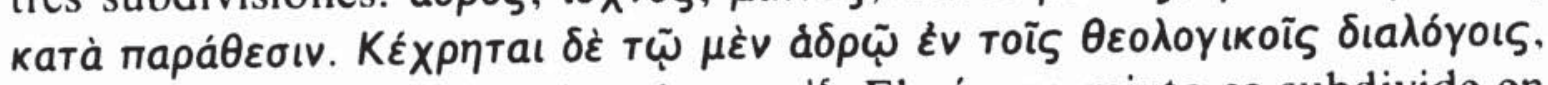

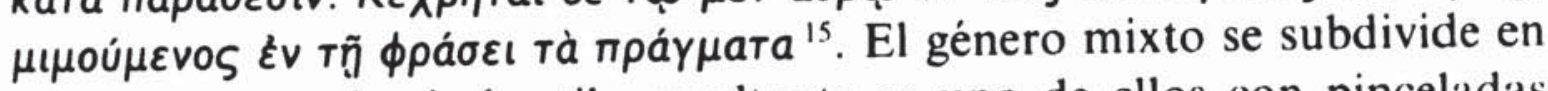
mixto por mezcla si el estilo resultante es uno de ellos con pinceladas

12 Por citar algunas fuentes de la misma idea: Proclo, In Alcibiadem 10, 3-14, y también Olimpiodoro, In Alcihiadem 56, 14-16.

${ }_{13}$ Muy similar Olimpiodoro, In Alcibiadem 65, 12-15.

14 Anonymous Prolegomena... XVI 31-35. Como fuente: Proclo, Alc. 18, 13-19, 1 .

15 Anonymous Prolegomena... XVII 1-3. Lo restante: XVII 5-15. La distinción entre los tres parece remontarse a Teofrasto aunque es dificil precisar si la terminologia es también suya, cf. R. Volkmann, Die Rhetorik der Gricchen und Romer. Hildesheim 1963 (1885), p. 534. 


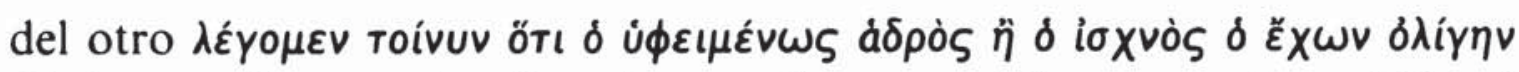

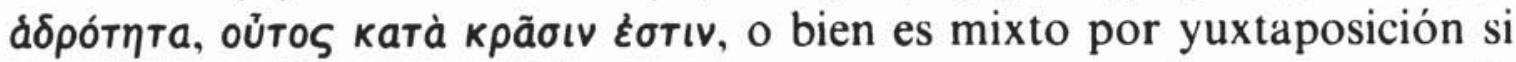
conviven en el mismo diálogo trozos en uno u otro estilo, como sucede en el Gorgias. En él lo que precede al mito tiene un estilo "simple» mientras que el mito lo tiene "amplio» ${ }^{16}$. La regla es lo que lo «teológico" tenga estilo elevado y lo "lógico" llano porque hay imitación en el estilo del tipo de asunto tratado. La forma sigue al contenido. Del mixto por mezcla usa en los diálogos éticos, porque también las virtudes ocupan un puesto medio ${ }^{17}$. La clasificación es un ejemplo perfecto de apriorismo, de superposición de criterios éticos a la materia literaria. La

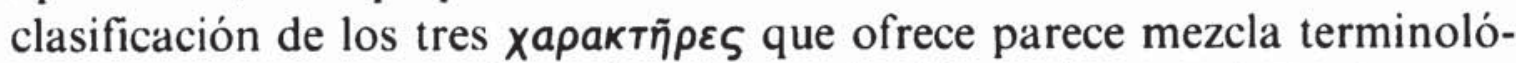
gica, por lo menos en el empleo de $\mu$ ıктós. Normalmente el término em-

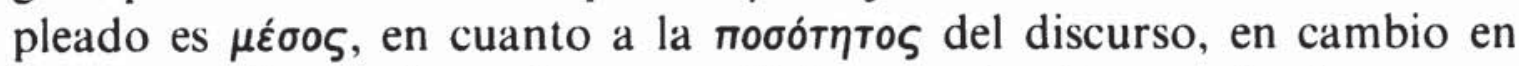

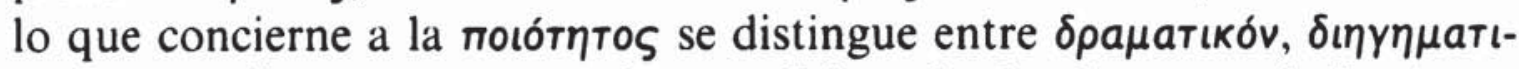
кóv, $\mu$ кктóv ${ }^{18}$. Parece que es de esta última de donde surge el término y el concepto. Implícito está ya desde Cicerón que el estilo medio uicinus amborum, in neutro excellens, utrisque particeps, uel utriusque, si uerum quaerimus, potius expers ${ }^{19}$. Interesantísimo el particeps ciceroniano que es lo que más se aproxima a la formulación del comentarista. Es necesario recalcar que en la tradición retórica más antigua no se distingue entre las dos posibilidades de realización del estilo medio ${ }^{20}$ y sin embargo es la que puede estar más cerca, sobre todo en el mixto por mezcla, de lo que actualmente puede aplicarse si se habla de estilo a la obra platónica ${ }^{21}$. Y con ello enlazamos con el punto siguiente que parece recoger en su núcleo elemental la última clasificación retórica enunciada.

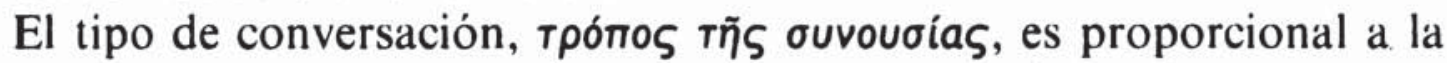

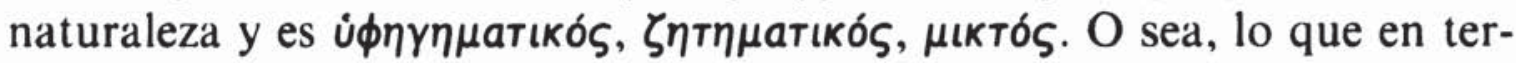
minología más reciente llamaríamos estructura general del diálogo. Y es «instructiva» cuando uno desarrolla su opinión sin investigación y prueba. $\mathrm{Y}$ nosotros podemos interpretar que esta modalidad se da cuando

16 Verdaderamente notable cómo el prejuicio de que a un contenido elevado le debe corresponder un estilo elevado les puede llevar a entender como tal el estilo del mito que es de una simplicidad asombrosa, cf. E. Ruiz Yamuza, El mito como estructura formal en Platón, Sevilla 1986, passim.

17 Quizá no sea excesivo recordar que es así desde la Ética Nicomaquea 2, 6, p. $1106 \mathrm{~b} 18$.

is R. Volkmann, pp. 535-536.

${ }^{19}$ Cicerón, Orator 5, 20. R. Volkmann aduce una cita de Proclo en Focio que in-

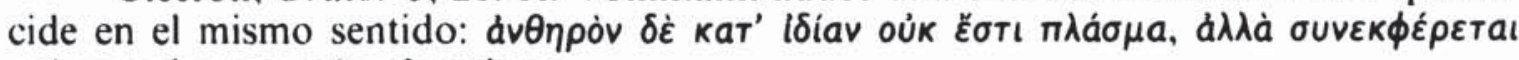

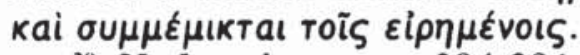

20 H. Lausberg, pp. 394-396. Sin el testimonio de Cicerón.

21 De hecho la noción de mixto por mezcla es casi lo que H. Thesleff, Studies on the styles of Plato, Helsinki 1967, emplea y es ya un clásico. 
la estructura es de exposición larga. Lo mismo se dice de los otros tipos $y$, aunque nunca se asocia con una estructura de manera explícita, puede deducirse con facilidad que los dos tipos restantes corresponden, el primero a estructura dialógica estricta, el segundo a lo que ahora llamamos diálogo tendiendo a monólogo. Cada uno de ellos se subdivide, a su vez, en otros dos: el instructivo es político o teórico. El inquisitivo en agonístico, competitivo, y en gimnástico ${ }^{22}$. Las diferencias en el primer caso parecen ser más bien temáticas, mientras que en el segundo es diferencia gradual: en el tipo agonístico importa primariamente la victoria sobre el interlocutor-contendiente. La clasificación recoge, en mi opinión, la tripartición, ya aristotélica y de la retórica posterior ${ }^{23}$, de la

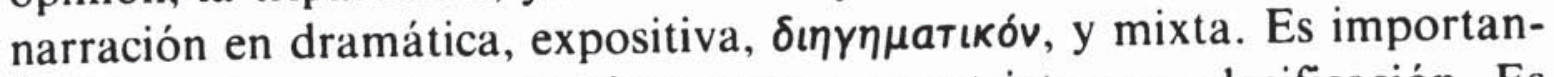
te, sin embargo, observar cómo nunca es estricta una clasificación. Es decir, que el criterio inicial, el que sea, no suele mantenerse ni dar lugar a ulteriores subdivisiones. Y los criterios barajados en este caso son estructurales, temáticos y teleológicos.

Los restantes elementos constitutivos del cosmos concebido como

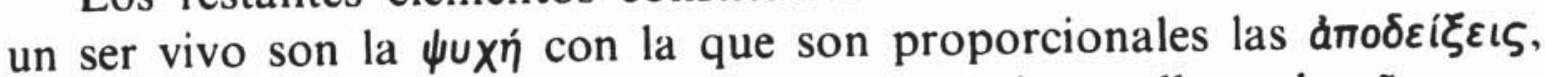
los argumentos, porque es el alma la que los desarrolla y el voũ cuya analogía es el про́ $\beta \lambda \eta \mu$, la cuestión que se plantea, en torno al cual «los argumentos se disponen a manera de una circunferencia, y con verosimilitud se dice que el problema se asemeja a la inteligencia: de la misma manera que no es divisible el intelecto y se concibe como el centro, en torno al cual están los procesos discursivos, como circunferencia que gira en torno a su centro, así el problema, y en su torno, a modo de circunferencia, los argumentos giran intentando captar la respuesta» ${ }^{24}$. Por último con la divinidad es proporcional la idea del bien.

Hay algunas observaciones marginales que no por ello dejan de tener lecturas oblicuas interesantes desde el punto de vista de la crítica literaria. Se dice, por ejemplo, que no es correcto subdividir un diálogo

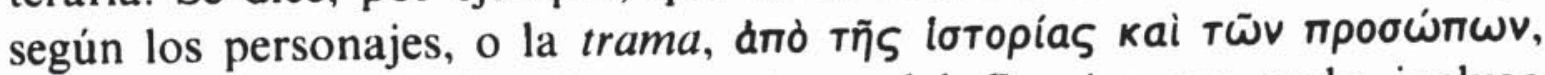
que intervienen. El ejemplo concreto es del Gorgias que suele, incluso modernamente ${ }^{25}$, dividirse en variados Agones, entre, p. ej., Gorgias-Sócrates-Polo etc. Su argumento se basa en algo que es cierto y demostra-

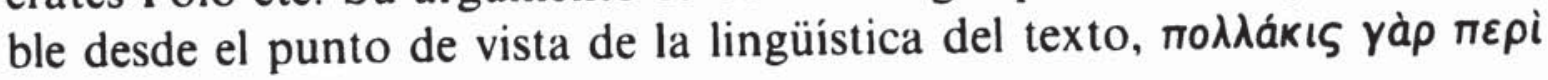

22 Anonymous Prolegomena... XVII 16-24.

23 Aristóteles, Poética 3; Fortunato, Ars Rhetorica III 9. H. Lausberg, Manual de retórica literaria, I, Madrid 1966 (1960), pp. 264-265.

24 Anonymous Prolegomena XVII 25-32.

is P. Bádenas de la Peña, La estructura del diálogo platónico, Madrid 1984, pp. 145-200. 


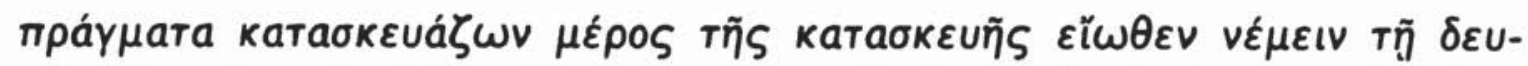

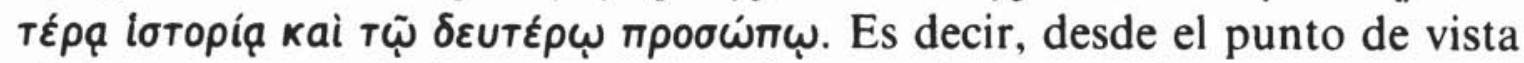
de la estructura de los contenidos, éstos están repartidos a lo largo del diálogo, que construye siempre, como unidad que es, una estructura acumulativa, un tejido de recurrencias y paráfrasis. Por tanto prima la unidad de la obra sobre entendimientos más parciales ${ }^{26}$. También se pronuncia contra el principio de división sobre la base de los silogismos, es decir sobre las estructuras complejas minimas que construyen el esqueleto de un parlamento, y ello porque «sobre un mismo asunto construye diversos silogismos de manera que no es posible llevar a término la demostración en un solo silogismo». La división en silogismos tiene un carácter evidentemente retórico; supone además que el diálogo se ha tratado como un discurso, cuando no siempre tiende a serlo, pero que en vez de hablar de entimemas, al tratarse de temática filosófica, se vuelve al término inicial. Es importante advertir el largo camino de aplicación de la noción en lo que en sentido amplio podemos llamar crítica literaria antigua, y destacan la universalidad de aplicación del concepto, mucho más allá de los límites en que Aristóteles pudo concebirlo. Llamativa es también la sustitución del entimema por silogismo, en la que ha vencido la temática sobre la mera forma de exposición. La propuesta alternativa de división, enmarcada perfectamente en el cuadro

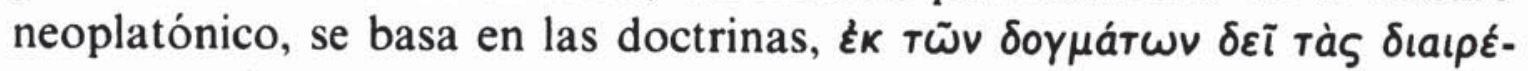

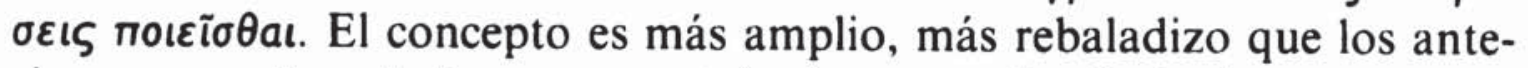
riores, pero tiene la inmensa ventaja de no quedar limitado a una zona peculiar de la obra literaria sino diluido, si se me permite, en toda su extensión. Tal idea casa perfectamente bien ${ }^{27}$ con la importancia que dentro del sistema filosófico neoplatónico adquiere la comprensión del Uno y cómo del Uno deriva lo Múltiple. O, por decirlo de otra manera, la unicidad de la obra literaria, en contenido y finalidad, es la resultante ineludible de la aplicación a la crítica literaria de la metafisica de la escuela.

En el mismo comentario bajo el apartado «modo de conversación de los personajes» se encuentran algunas observaciones interesantes; éste se realiza por medio de los personajes directamente, como cuando se presenta a Sócrates hablando con algún otro. O por medio de otros que lo oyeron de los mismos personajes, como cuando alguno cuenta alguna conversación que le oyó a Sócrates, o de alguno que a su vez la oyó y la procesión podría continuar. Ello aliñado con la idea habitual

${ }^{26}$ Anonymous Prolegomena XIX 7-9. Y, en general, en todo el XIX.

${ }_{27}$ Coulter, p. 73 ss. y especialmente p. 78. Las fuentes concretas en Westerink, comentario de las mismas en Coulter, p. 85 ss. 
de la procesión que provoca que nunca se avance más allá del tercer grado que es donde acaban los seres dotados de intelecto. La distinción entre estilo directo e indirecto se le va de las $\operatorname{manos}{ }^{28}$. Notable la aparición del mismo término трб́по бuvouoías, con dos variantes, la prime-

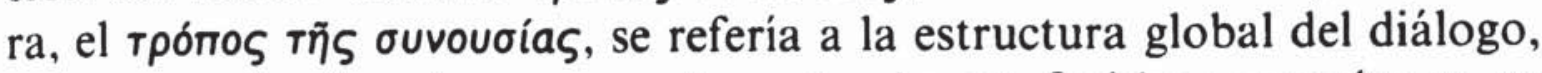

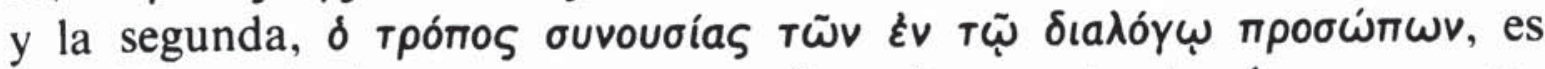
esta última. Ambas son puramente formales y estructurales y, por supuesto, se superponen una a la otra y podemos decir que tienen su origen en la misma cuna: la nolórns de la estructura narrativa.

El capítulo siguiente, 21 , se dedica al establecimiento de las reglas,

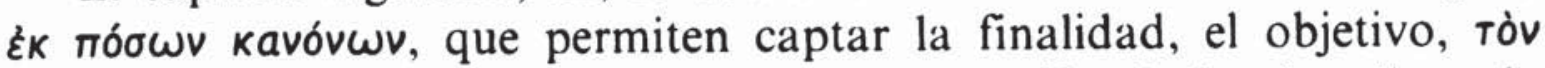
бкопóv, de cada diálogo. La unicidad de intención de la obra literaria condiciona el tipo de necesidad inherente a sus elementos y tiene su cuna por lo menos en el Fedro ${ }^{29}$ platónico. La conveniencia de fijar un método se ve refrendada por la ausencia de un criterio unitario a la hora de establecer la finalidad de cada diálogo, tal y como se refleja en los dobletes de los títulos de los mismos. Establece que a partir de diez

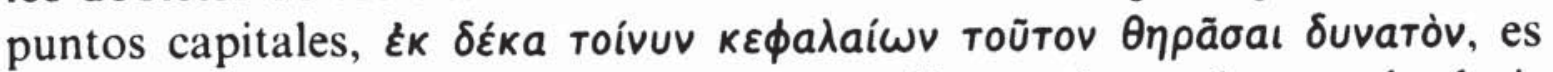
posible encontrarlo. Los diez puntos son dicotomías en las que la decisión se hace siempre en el sentido de la considerada positivamente: aplicando el criterio de lo uno y lo múltiple, de manera que se sostiene que el diálogo tiene siempre un solo objetivo y no muchos; siguiendo con la

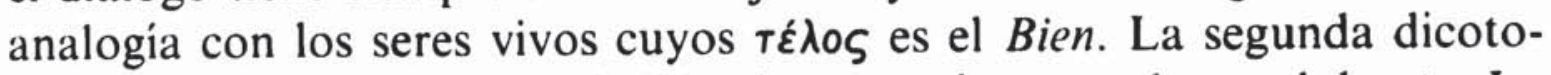
mía hace que se vuelva preferible el tema más general y englobante. La tercera la constituye la pareja parte frente a todo. La cuarta lo aproximado frente a lo seguro. La quinta lo mejor frente a lo peor. La sexta

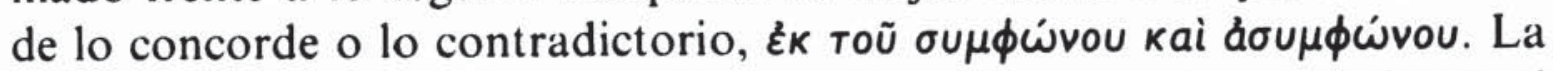
séptima que nunca cabe entender que la crítica negativa constituya el

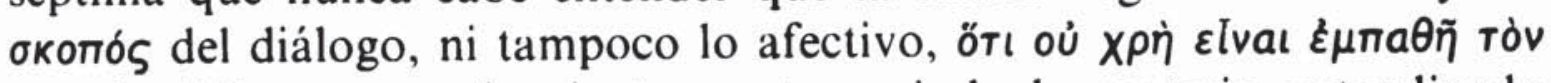
бкопі̀v. Ni tampoco los instrumentos, ni de la materia entendiendo como tal a los personajes. Por supuesto ${ }^{30}$, de la primera regla adquieren su fundamento todas las demás. Pueden agruparse, siguiendo a Coulter $^{31}$ en tres grupos: las que son resultado de un método filosófico que se concibe como deseable, la segunda y la cuarta, las que resultan de planteamientos éticos, la quinta, la séptima y la octava, y las que reve-

\footnotetext{
2* Anonymous Prolegomena... XX.

2) Phdr. 64c, 237b.

"11 J. A. Coulter, p. 82.

"J. A. Coulter, p. 83 ss.
} 
lan una estructura conceptual peculiarmente neoplatónica, tercera, sexta, novena y décima ${ }^{32}$.

En cuanto al orden de la obra platónica, se distingue, de modo más claro que en los predecesores, entre un orden temporal, que es doble: el tiempo de composición y el de los personajes de los diálogos y el orden en tetralogías. En cuanto al tiempo de composición, se decía que el primero había sido el Fedro, porque en él se planteaba la cuestión de la escritura, y con un argumento de estilo: porque tiene estilo ditirámbico. El último lugar lo ocupan las Leyes, que dejó inacabadas y cuya última revisión se debe a Filipo de Opunte. La edad de los personajes la marca la figura de Sócrates y según este criterio el primero será el Parménides, que lo presenta muy joven, aún bajo la enseñanza de Parménides, y el último el Teeteto, que tiene lugar después de la muerte de Sócrates. El último criterio, las tetralogias ${ }^{33}$, queda bastante invalidado por el carácter espurio de la Epinomis, ya establecido por Proclo, y necesaria para completar el número. La primera y la última obra, Eutifrón, Epistolas, compartirían el carácter biográfico: en su caso se trata de la vida de Sócrates y en el otro de la de Platón. Se desecha el criterio por el rechazo platónico a $\varepsilon \grave{\delta} \delta \omega \lambda a \varepsilon l \delta \omega \lambda \omega v$, porque la finalidad sea el placer y, con un argumento absolutamente consistente, porque carecen de oxonós unitario, es decir el criterio no tiene coherencia ni solidez ${ }^{34}$. Su clasificación empieza con la discriminación de los diálogos considerados no auténticos. Se apartan Sisifo, Alción, Erixias, Definiciones que se atribuyen a Espeusipo. Da una noticia contradictoria que dificilmente puede ser

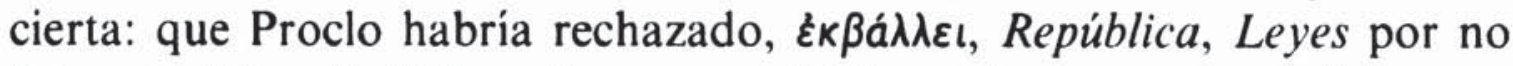
tener carácter dialógico. Pero no es lógico entonces que escribiera un comentario a la primera de ellas, también habría dejado a un lado las Epistolas, por la simplicidad del estilo, pero añade a continuación: «si a éstas le añadimos los doce libros de la Leyes y los diez de la República nos quedan cincuenta y cuatro diálogos». Parece más lógico entender que Proclo para un acercamiento primerizo a la obra del maestro habría considerado poco rentables las dos grandes obras citadas y no los habría incluido como necesarios en un curso de lectura inicial. Siguiendo a Jámblico, de todos ellos se establece un grupo de doce que se en-

32 Las fuentes últimas de la teoría pueden encontrarse en Jámblico, y su desarrollo eficaz en Proclo, cf. In Alc. 7,18-8,1; 8,1-3, 3-5; 18,15-16. Por poner sólo algunos ejemplos.

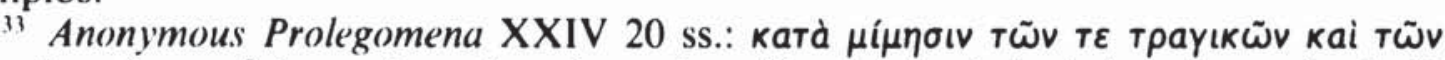

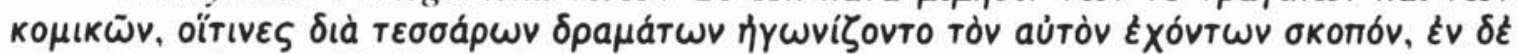

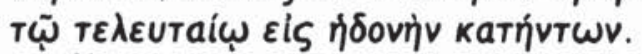

${ }^{34}$ Es de hecho imposible encontrar el hilo conductor de las tetralogías tal y como las exponen Albino o Diógenes Laercio. 
cierran en dos: Timeo, Parménides, el primer versando en torno al mundo fisico, el segundo de tema teológico. $\mathrm{Y}$ es el orden de lectura de los seleccionados el que se vuelve importante. El primer lugar lo ocupa el Alcibiades, luego van Georgias, Fedón, Crátilo, Teeteto, Fedro, Banquete, Timeo, Parménides, Filebo.

La última zona de los Prolegomena está ocupada por los modos de

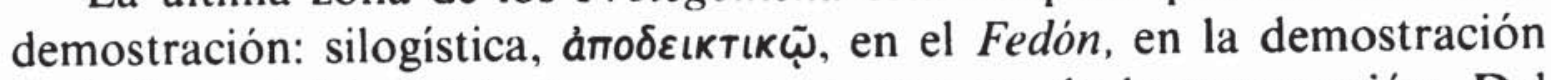
de la inmortalidad del alma por el argumento de la automoción. Del

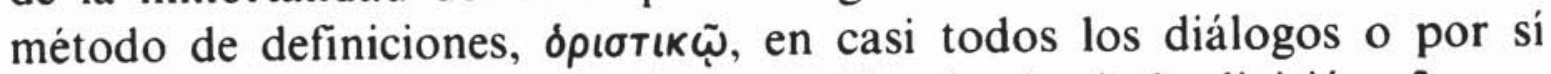

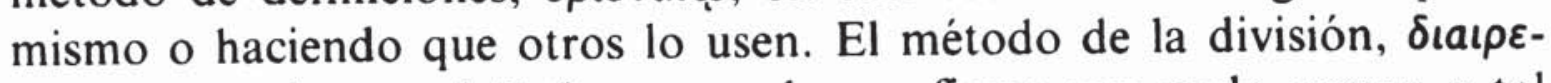

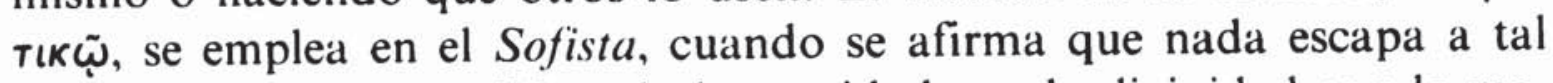
método que fue concedido a la humanidad por la divinidad con la mediación de Prometeo. Del analítico en Timeo, cuando resuelve todos los seres naturales en forma y receptáculo. Del de evidencia indirecta, $\tau \varepsilon \kappa \mu \eta \rho \iota \omega \delta \varepsilon \iota$, en Alcibiades, cuando dice que es testimonio de la mentira la falta de acuerdo, de la verdad el acuerdo. Del metafórico, عikovıкū,

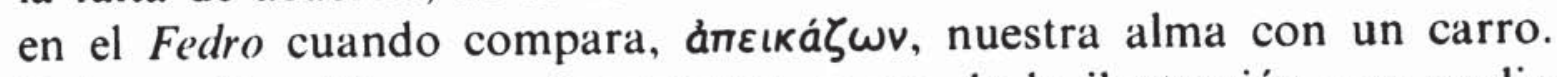

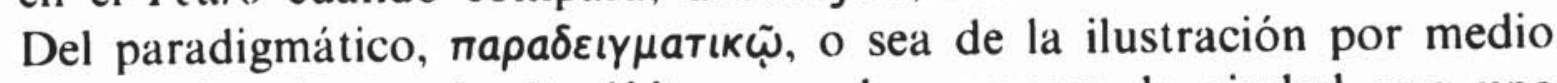
de un ejemplo, en la República cuando compara la ciudad con una nave, al pueblo con la tripulación. La diferencia entre un método y otro estriba en que el metafórico muestra de un modo más eficaz e imita me-

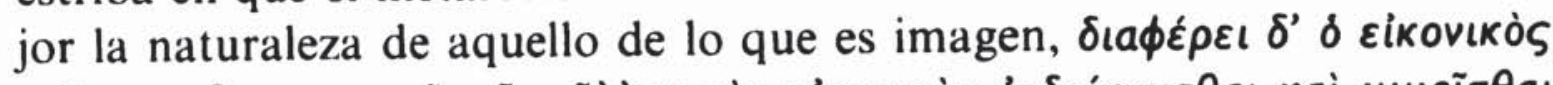

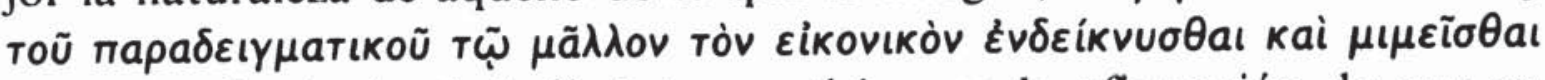

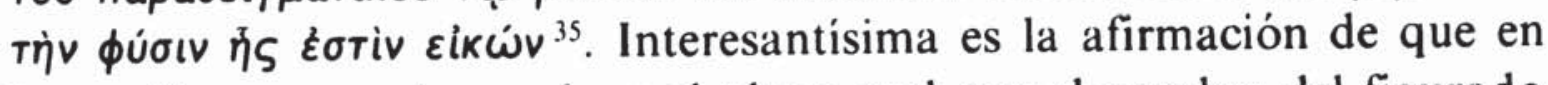
la metáfora se puede nombrar el plano real con el nombre del figurado

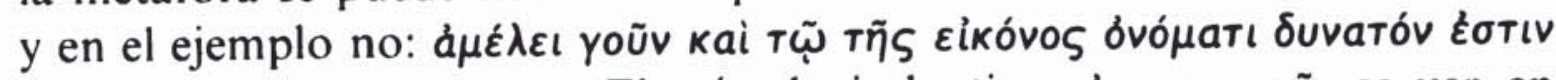

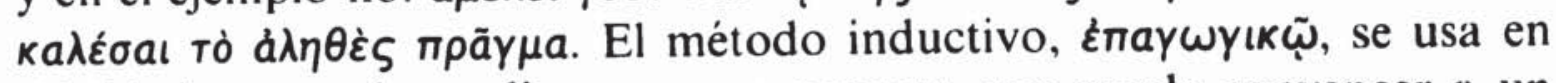
Alcibiades, cuando se dice que una persona que puede convencer a un hombre puede también convencer a la multitud. Del analógico, ávào$\gamma \iota \kappa \tilde{\varphi}$, en el Gorgias, en las proporciones entre cocina/medicina, judicatura/sofistica. Del matemático en el Filebo, cuando numera los órdenes del bien. Del método de abstracción, áфаıретıкй, en Timeo, cuando encuentra y establece la materia porque prescinde de todas las formas.

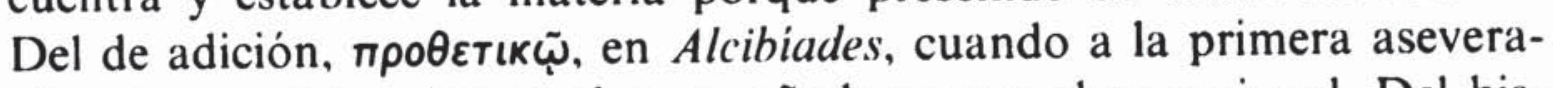
ción de que el hombre es alma se añade que es alma racional. Del histórico en las Leyes en que narra la historia desde el cataclismo hasta las guerras Médicas y por último del etimológico en Teeteto.

${ }^{3}$ Anonymous Prolegomena XXVII, para toda la cuestión y la última referencia, 29-33. 
Las fuentes primarias del pasaje son proclianas ${ }^{36}$ aunque hay diferencia apreciable en el uso del término "icónico" ${ }^{37}$. En el sistema de Proclo ${ }^{38}$ el término establece oposición con "símbolo" y ambos quedan definidos como formas diferentes del mito. El primero de ellos, el icónico, mantiene correspondencias entre todos los elementos, del plano expreso y del supuesto plano figurado ${ }^{39}$. Mientras el segundo no tiene correspondencias tan estrictas. En cuanto a su sentido, lo que está quizás en la base del razonamiento procliano es la noción de analogía ${ }^{40}$. En cambio lo que tenemos en los Prolegomena altera totalmente el sentido

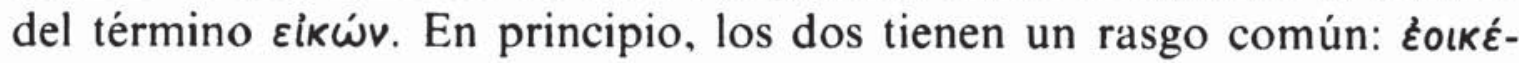
val, y una diferencia específica: $\mu \tilde{a} \lambda \lambda \lambda_{0} v$,

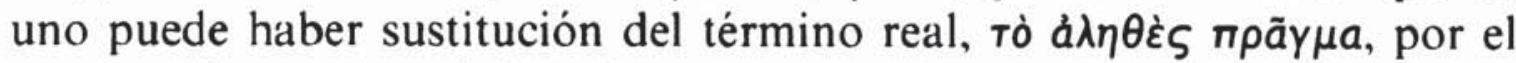

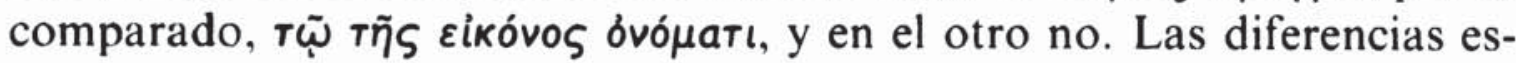
tablecidas son estrictamente distribucionales y funcionales. Otra cosa es que la razón última del mecanismo la proporcione una causa que ya es en sí extranligüística: $\mu \tilde{a} \lambda \lambda$ ov $_{\text {źoı́ }}$ val, y que deviene poco coherente si se aplica.

Los términos que se oponen son $\varepsilon i k \omega ́ v-\pi a \rho a ́ \delta \varepsilon ı \gamma \mu a$ y hasta cierto punto constituye una innovación su aplicación para diferenciar lo que es metáfora de lo que es comparación. El concepto no aparece con precisión relativa hasta la Retórica de Aristóteles ${ }^{41}$, donde se distingue en-

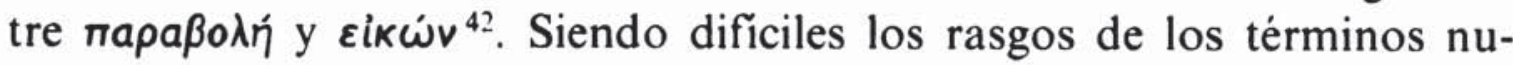
cleares, hay, no obstante, una observación importante que hacer que quizás venga de manera indirecta a añadir base a la observación de Solmsen ${ }^{43}$ de que el auténtico núcleo de la obra aristotélica lo constitu-

${ }^{36}$ Más ejemplos del modo de exposición entusiástico en Olimpiodoro, Commentary on the first Alcibiades of Plato, critical text and notes by L. G. Westerink, Amsterdam 1956, 2, 1-13. Donde se mencionan además lugares de Timeo, Fedro, Teeteto.

${ }^{37}$ Proclo, In Rempublicam II 8, 11-14; In Parmenidem 646, 28-31; Theologia 9, 8-29.

${ }^{38}$ Proclo, In Remp. II 205, 1-16; 355, 19-20.

${ }^{39}$ Coulter, p. 69 ss.

40 Pero no estoy en absoluto de acuerdo con que la estructura del mito del carro alado esté construida sólo a base de analogía. La que hay la explicita el propio autor, pero se desplaza inmediatamente a una metáfora intensa con fusión de planos. En contra Coulter, p. 42.

${ }^{41}$ Los testimonios prearistotélicos suelen tener un término englobante para metáfora y comparación, cf. M. H. McCall, Ancient Rhetorical Theories of Simile and

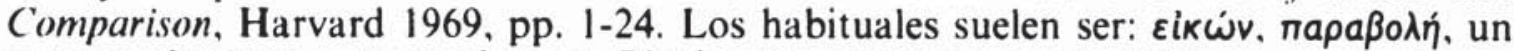

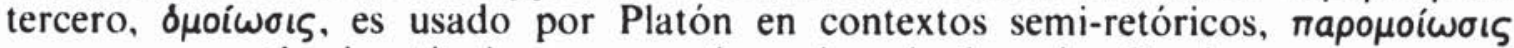
aparece como término técnico pero no tiene vigencia después. El primero es con mucho el más usado.

${ }^{42}$ Aristóteles, Retórica II, XIX y XX.

${ }^{43}$ F. Solmsen, "The aristotelian tradition in Ancient Rhetoric" (1941), ahora en Rhetorika Scriften zur aristotelischen und hellenistichen Rhetorik, Hildesheim 1968, pp. 312-349 y en concreto 316 . 
ye la doctrina de las koıvai níoreıৎ cuyo fundamento último se obtiene de la teoría lógica del filósofo. Tengamos en cuenta que una parte de las opiniones sobre la comparación y la metáfora se hallan en el libro II que trata, no de la expresión formal como suponerse pudiera, sino

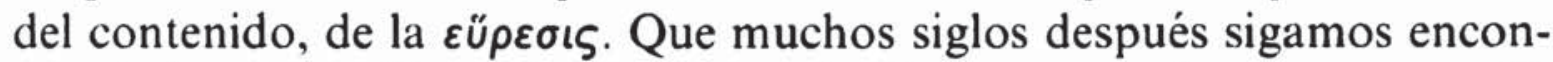
trando la misma distinción, con las salvedades que ya haremos, no aplicada a estructuras formales sino a arquitecturas mentales, y que esta aplicación se haga dentro de la Escuela Neoplatónica de Alejandría, en la que hubo un especialísimo interés por la obra del Estagirita, prueba la existencia de una corriente que vinculaba directamente con la lógica todo el contenido fundamental de la Retórica. De los términos usados,

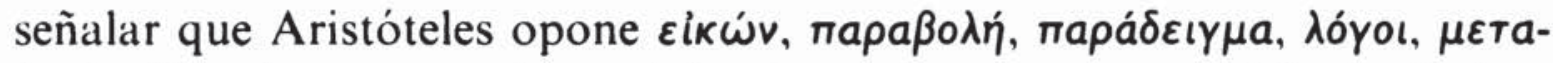

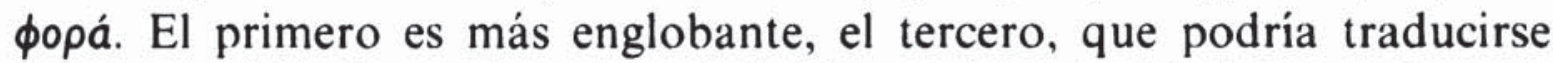
como paralelo ilustrativo, se subdivide en ejemplo histórico o factual,

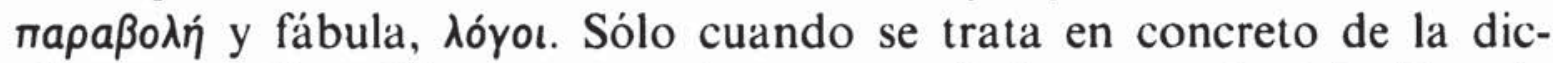

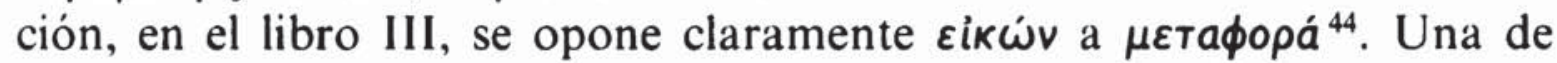
las claves para distinguir una de la otra es que no identifica los elemen-

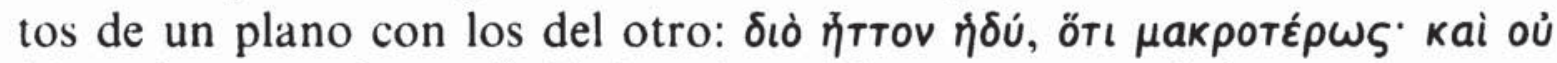

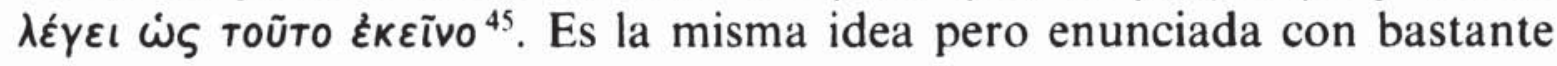
menos claridad que en nuestro anónimo. Con la salvedad de que ha usado los términos que en Aristóteles aparecen cuando se habla en general de la comparación desde el punto de vista de la estructura de contenido, no los que aplica cuando se trata de expresión formal. Importante es que la distinción así enunciada no es de común aparición en los tratadistas posteriores que insisten en la brevedad de la metáfora, en su

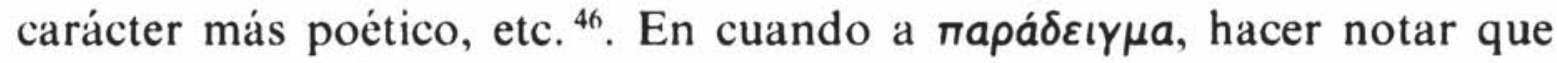
ya en Plutarco ${ }^{47}$ empieza a usarse de modo más genérico, saliendo del marco de aplicación del ejemplo histórico o factual y bien establecido en Trifón en un sentido más preciso.

Encuentro asimismo una serie de concordancias interesantes entre los métodos de exposición y los capítulos de la Retórica en que se tratan las fuentes de las que pueden obtenerse entimemas demostrativos. Aristóteles señala que pueden obtenerse entre otras posibilidades de las

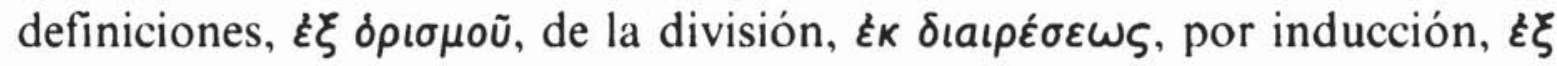

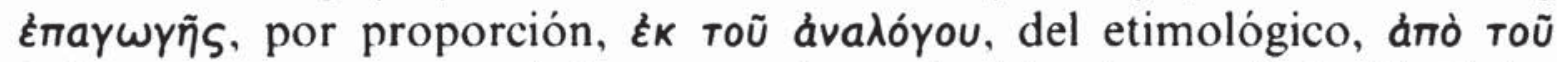
ovóparos, por marcar únicamente las coincidencias verbales ${ }^{48}$. Tales

\footnotetext{
44 Aristóteles, Retórica III 4.

45 Aristóteles, Retórica III 10. Cf. McCall, pp. 40-41.

46 Teniendo en cuenta además que la parte correspondiente en Longino no ha llegado hasta nosotros.

47 McCall, p. 241.

4* Aristóteles, Retórica II, XXIII y, en especial, VII, IX, XXVI, XXVIII.
} 
concordancias pueden interpretarse en el mismo sentido anteriormente enunciado.

Es evidente que los modos de exposición que acabamos de enumerar se formulan sobre bases no unitarias. En primer lugar sería posible una primera distinción entre los puramente racionales, los suprarracionales, los que proceden de un concepto de la psique humana. Como arquitecturas expositivas puramente racionales entendemos los siguientes: demostración silogística, definición, división, análisis, evidencia indirecta, método inductivo, analógico, aritmético, abstracción y adición y el etimológico. Como puramente suprarracional el método entusiástico. Como producto de una psicología especial, el comparativo y el metafórico. Como resultado de la adquisición del concepto «historia», como un campo nuevo y específicamente humano, el histórico. Atendiendo únicamente a esta exposición nos queda una concepción del ser humano no sólo global sino acumulativa: el hombre es un ser racional, no el último eslabón en la cadena de los seres dotados de intelecto, especialmente sensible a lo literario e histórico. $\mathrm{Y}$ todos ellos son términos que se han usado, diacrónicamente, para intentar captar globalmente la esencia del hombre.

Como aportaciones importantes a lo que podemos llamar crítica literaria antigua tenemos, desde el punto de vista conceptual: la puesta en escena de la intención del autor, que se entiende como subyacente en toda la obra, el criterio, mantenido de forma absolutamente coherente, de la unicidad y organicidad de la obra, la presencia y la consideración del lector. Desde el punto de vista más específico de qué aporta al entendimiento de Platón escritor, tenemos que resaltar que se trata de una superación del entendimiento de la obra platónica casi como si fuera orador, que es lo que solemos encontrar en los manuales de Retórica, que concentran su atención sobre algún discurso aislado y que nunca tratan un diálogo como unidad ${ }^{49}$. Por otra parte, se trata de un estudio bastante exhaustivo: cronología posible, definición del género, autentificación de lo conservado, definición de los constituyentes mínimos e incluso acercamiento al creador de literatura en las relaciones que mantiene con su obra.

\section{Emilia Ruiz Yamuza}

${ }^{49}$ G. M. A. Grube, The greek and roman critics, Londres 1965, p. 229: "The great weakness of the rhetorical kind of criticism through the centuries was that it focused attention upon this or that quality of style, upon this or that aspect in the handling of subject-matter and used great literature merely as a storehouse of examples for the successful application of the formulae." 